\title{
Firn accumulation records for the past 1000 years on the basis of dielectric profiling of six cores from Dronning Maud Land, Antarctica
}

\author{
Goen M. HOFSTEDE, ${ }^{1}$ Roderik S.W. van de WAL,${ }^{1}$ Karsten A. KASPERS, ${ }^{1}$ \\ Michiel R. van den BROEKE, ${ }^{1}$ Lars KARLÖF, ${ }^{2}$ Jan-Gunnar WINTHER, ${ }^{2}$ \\ Elisabeth ISAKSSON ${ }^{2}$ Gante LAPPEGARD,${ }^{3}$ Robert MULVANEY, ${ }^{4}$ \\ HANS OERTER, ${ }^{5}$ Frank WILHELMS ${ }^{5}$ \\ ${ }^{1}$ Institute for Marine and Atmospheric Research Utrecht, P.O. Box 80.005, Utrecht University, Princetonplein 5, \\ 3584 CC Utrecht, The Netherlands \\ E-mail:r.vandewal@phys.uu.nl \\ ${ }^{2}$ Norwegian Polar Institute, Polar Environmental Centre, N-9296 Tromsø, Norway \\ ${ }^{3}$ Department of Geosciences, University of Oslo, P.O. Box 1042, Blindern, N-0316 Oslo, Norway \\ ${ }^{4}$ British Antarctic Survey, Natural Environment Research Council, Madingley Road, Cambridge CB3 0ET, England \\ ${ }^{5}$ Alfred-Wegener-Institut für Polar-und Meeresforschung, Columbusstrasse, D-27568 Bremerhaven, Germany
}

\begin{abstract}
This paper presents an overview of firn accumulation in Dronning Maud Land (DML), Antarctica, over the past 1000 years. It is based on a chronology established with dated volcanogenic horizons detected by dielectric profiling of six mediumlength firn cores. In 1998 the British Antarctic Survey retrieved a medium-length firn core from western DML. During the Nordic EPICA (European Project for Ice Coring in Antarctica) traverse of 2000/01, a $160 \mathrm{~m}$ long firn core was drilled in easternDML. Together with previously published data from four other medium-length ice cores from the area, these cores yield 50 possible volcanogenic horizons. All six firn cores cover a mutual time record until the 29th eruption. This overlapping period represents a period of approximately 1000 years, with mean values ranging between 43 and $71 \mathrm{~mm}$ w.e. The cores revealed no significant trend in snow accumulation. Running averages over 50 years, averaged over the six cores, indicate temporal variations of $5 \%$. All cores display evidence of a minimum in the mean annual firn accumulation rate around AD 1500 and maxima around $\mathrm{AD} 1400$ and 1800 . The mean increase over the early 20th century was the strongest increase, but the absolute accumulation rate was not much higher than around AD 1400. In eastern DML a 13\% increase is observed for the second half of the 20th century.
\end{abstract}

\section{INTRODUGTION}

The European Project for Ice Coring in Antarctica (EPICA) uses two drilling sites: in the Indian Pacific sector at Dome Concordia (Dome C) and in the Atlantic sector in Dronning Maud Land (DML) (Fig. 1). At each site, several medium-length firn cores have already been drilled in addition to one deep core. In 1997/98, cores B31-B33 were retrieved from DML by the Alfred-Wegener-Institut für
Polar- und Meeresforschung (AWI), Bremerhaven (Oerter and others, 2000; Sommer and others, 2000a, b; Traufetter and others, in press). In 1998, cores CV and BAS were retrieved at Camp Victoria (Karlöf and others, 2000) and the fuel depot of the British Antarctic Survey (BAS) respectively. During the Norwegian Antarctic Research Expedition (NARE) 2000/01, a medium-length firn core, M150, was drilled at site M on the DML plateau (Winther and others, 2002). See Figure 1 and Table 1 for all core locations.

Table 1. Location, height and some physical properties of the six firn cores

\begin{tabular}{cccccccc}
\hline Firn core & Location & $\begin{array}{c}\text { Height } \\
\mathrm{m} \text { a.s.l. }\end{array}$ & $\begin{array}{c}\text { Drill depth } \\
\mathrm{m}\end{array}$ & $\begin{array}{c}T_{10 \mathrm{~m}} \\
{ }^{\circ} \mathrm{C}\end{array}$ & $\begin{array}{c}\text { Accumulation } \\
\text { mm w.e. } \mathrm{a}^{-1}\end{array}$ & $\begin{array}{c}\text { Month/year of drilling } \\
\text { Source }\end{array}$ \\
\hline M150 & $75^{\circ} 00^{\prime} \mathrm{S}, 15^{\circ} 00^{\prime} \mathrm{E}$ & 3457 & 159.8 & -51.3 & 43 & Jan. 2001 & This paper \\
B33 & $75^{\circ} 10^{\prime} \mathrm{S}, 06^{\circ} 30^{\prime} \mathrm{E}$ & 3160 & 130.5 & -46.1 & 45 & Jan. 1998 & Oerter and others (2000) \\
B32 & $75^{\circ} 00^{\prime} \mathrm{S}, 00^{\circ} 00^{\prime} \mathrm{E}$ & 2882 & 149.9 & -44.5 & 62 & Dec. 1997 & Oerter and others (2000) \\
B31 & $75^{\circ} 35^{\prime} \mathrm{S}, 03^{\circ} 26^{\prime} \mathrm{W}$ & 2669 & 115.1 & -44.3 & 59 & Dec. 1997 & Oerter and others (2000) \\
CV & $76^{\circ} 00^{\prime} \mathrm{S}, 08^{\circ} 03^{\prime} \mathrm{W}$ & 2400 & 120.0 & -38.0 & 62 & Jan. 1998 & Karlöf and others (2000) \\
BAS-depot & $77^{\circ} 02^{\prime} \mathrm{S}, 10^{\circ} 30^{\prime} \mathrm{W}$ & 2176 & 121.7 & -37.7 & 71 & Jan. 1998 & This paper \\
\hline
\end{tabular}




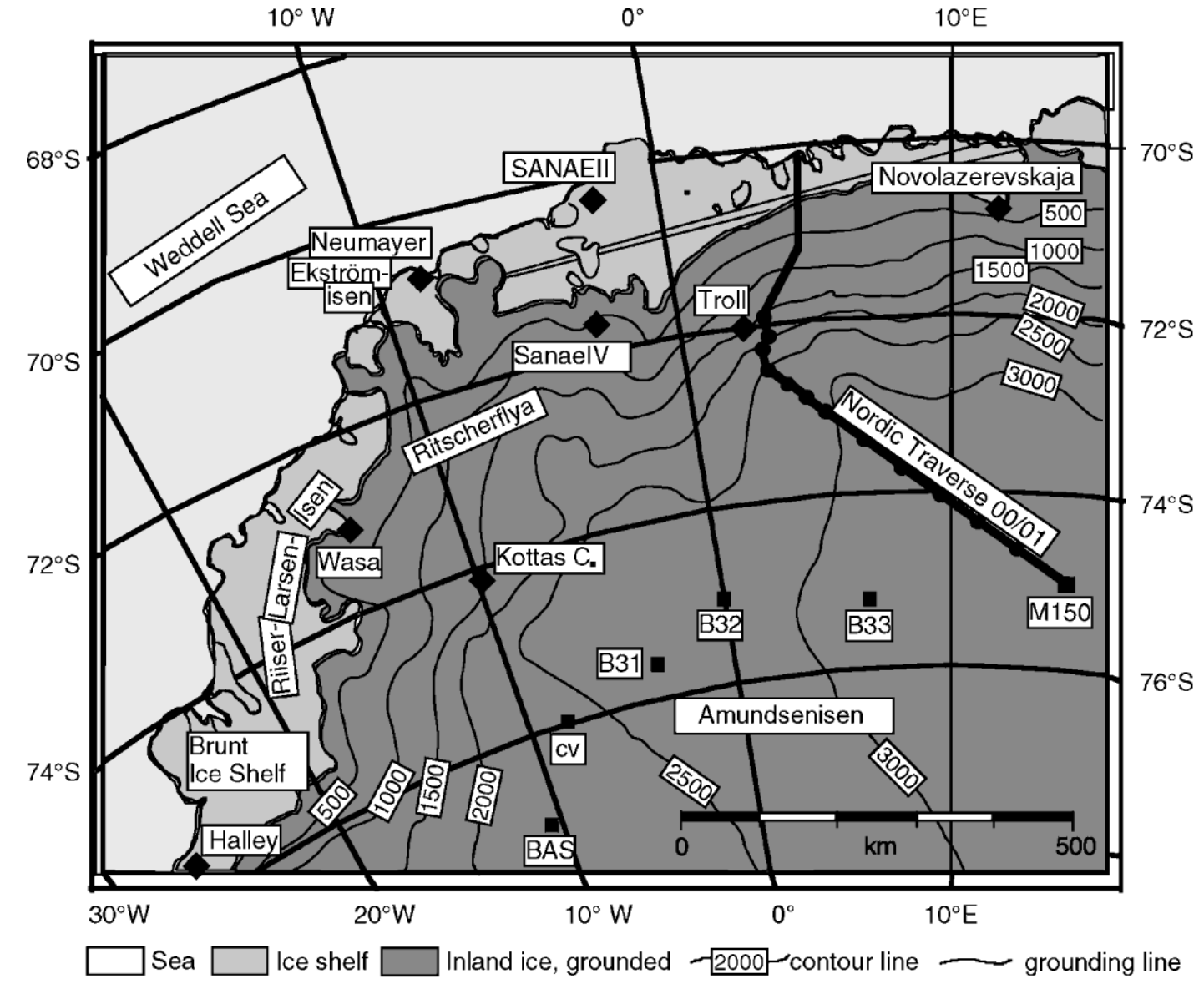

Fig. 1. Dronning Maud Land with the drilling locations of the six medium-length ice cores drilled in the period 1996-2001.

These six cores represent 1000 years of accumulation and can be used to obtain information on the spatial distribution of observed changes. In this paper, we present dielectric profiling (DEP) data for the M150 and BAS cores. We use our DEP data and the other four records (Karlöf and others, 2000; Oerter and others, 2000; Sommer and others, 2000a, b; Traufetter and others, in press) to derive long-term variations in accumulation rate for DML. This results in a spatial overview of the regional accumulation data, as three of the six records (BAS, CV and B31) are from the western part of DML and the other three are located approximately on the ice divide running from Dome $\mathrm{F}$ westwards (Fig. 1).

Section 2 covers the field conditions for M150 and BAS, while section 3 deals with the DEP analyses. Section 4 describes how chronologies for the six cores were established by identifying specific volcanic horizons in the DEP data. Dating of the events in cores B31-B33 is largely based on continuous flow analysis (CFA) (Sommer and others, 2000a) and non-sea-salt sulphate (nss) data (Traufetter and others, in press). Eruptions that are only radiocarbondated have been calibrated with the data of Stuiver and others (1998a; see Appendix). Section 5 concerns the variability of firn accumulation rates as derived from the DEP data. Section 6 contains the discussion and conclusions. The Appendix contains more detailed information on the dating of volcanic horizons.

\section{FIELD GONDITIONS}

Here, we describe the field conditions only for the M150 and BAS cores, as the field conditions for the other four cores have already been published (Karlöf and others, 2000; Oerter and others, 2000; Sommer and others, 2000a, b; Traufetter and others, in press). Both cores were drilled with a conventional electromechanical ice-core drill (e.g. Mulvaney and others, 2002b) in a dry borehole. Each drilling run produced a core $0.5-2 \mathrm{~m}$ long.

\section{M150 core}

A $500 \mathrm{~km}$ long traverse was undertaken, from the Norwegian base Troll to site $\mathrm{M}$ on the Antarctic plateau, during NARE 2000/01. The fieldwork is described in detail by Winther and others (2002). The total length of the core was $160 \mathrm{~m}$. The core sections were stored in temporary outside storage and covered with snow to keep their temperature as stable as possible. To analyze the core sections, a $15 \mathrm{~m}$ long underground snow laboratory was built. This protected the cores as much as possible from temperature variations and sunlight. In the laboratory, the temperature of the cores varied between $-15^{\circ}$ and $-25^{\circ} \mathrm{C}$. To make sure that the cores had adapted to laboratory temperature, the core sections were stored in the laboratory at least half a day before measurements started. The core sections were then analyzed with a DEP instrument. This was calibrated directly before the first section was measured and immediately after the last section was measured.

\section{BAS core}

A four-person team from the BAS retrieved a new mediumlength ice core from western DML near to the BAS fuel $\operatorname{depot}\left(77^{\circ} 02^{\prime} \mathrm{S}, 10^{\circ} 30^{\prime} \mathrm{W}\right)$ in January 1998 . The field team 


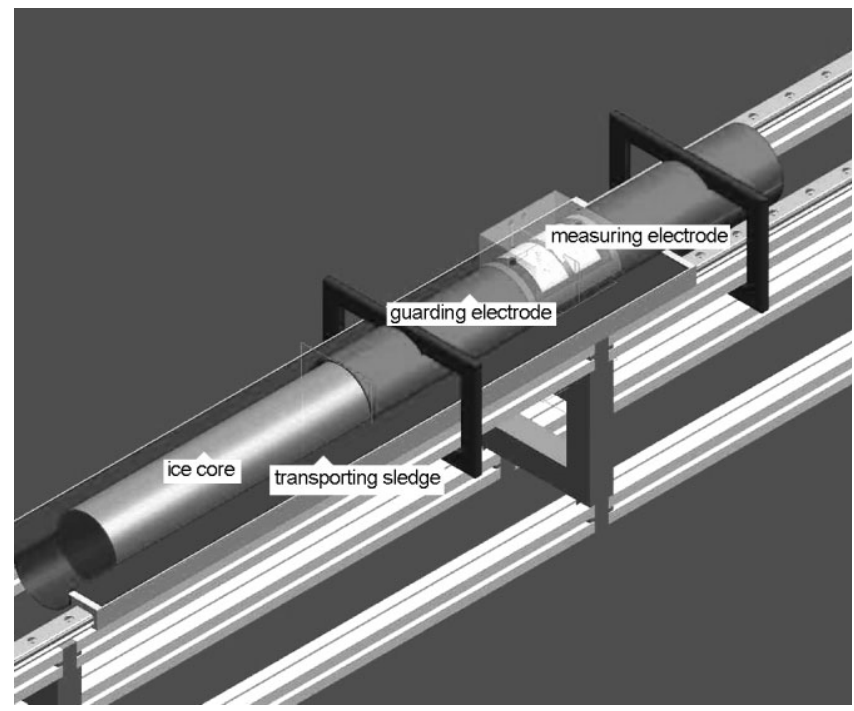

Fig. 2. The DEP instrument developed by Utrecht University. In this image, the transport sledge moves the ice core in steps through a tube-shaped capacitor for measurements, while the measuring electrode registers capacitance and conductance. The electrodes are tube-shaped so they can calculate the core's permittivity and capacity precisely.

and equipment were flown to the site by Twin Otter aircraft. The total length of the core was $121 \mathrm{~m}$. The core sections were logged, but no further analyses were carried out in the field. The cores were cut to a maximum length of $0.95 \mathrm{~m}$, then sealed in plastic, packed in cardboard tubes, stored in insulated boxes and buried in a snow pit (maximum logged pit temperature was $-20^{\circ} \mathrm{C}$ ). Once drilling was completed, the cores were lifted by Twin Otter and transported to Halley station, where they were stored in an $8 \mathrm{~m}$ deep shaft (constant temperature was $-18.6^{\circ} \mathrm{C}$ ). Three weeks later, they were transferred to a refrigerated container aboard the BAS supply ship RRS Bransfield for return to the U.K.; during shipment, the temperature was maintained at $-22^{\circ} \mathrm{C}$. Once returned to the UK laboratory, the cores were measured for DEP in a cold laboratory at $22^{\circ} \mathrm{C}$. Subsequently, the cores were sectioned for stable-isotope and other chemical analysis.

\section{DEP MEASUREMENTS}

For the M150 core, DEP analyses were carried out in the field during the NARE 2000/01 expedition. The DEP instrument used in these analyses was developed at Utrecht University (Fig. 2), based on the concept described by Wilhelms (1996) and Wilhelms and others (1998). The B31-B33 and CV cores were measured by the AWI's DEP instrument. The main difference between the two versions is the transport mechanism for the ice cores. In the AWI version the cores are suspended in foil, whereas in the Utrecht instrument the cores are transported by a sledge with a hammock in which a core section is placed. The Utrecht version saves time in preparing the cores for measurement since suspending the cores in foil is more labour-intensive. Electronically, the two devices are identical. The DEP signal was a $250 \mathrm{kHz}, 1 \mathrm{~V}$ signal. The firn cores were measured every $5 \mathrm{~mm}$ with a $10 \mathrm{~mm}$ measuring electrode. The BAS core DEP profile is presented as the $50 \mathrm{kHz}$ conductance, with a resolution of $1 \mathrm{~cm}$. In the BAS instrument, the cores are in fixed position and the measuring electrodes are transported. The BAS instrument is therefore neither mechanically nor electronically identical to the other two instruments.

Based on the DEP measurements, the bulk a.c. capacitance and conductance were determined (Moore and Paren, 1987; Moore and others, 1992; Wilhelms, 2000). Permittivity and conductivity were derived from these quantities (Wilhelms, 2000). Density was calculated by means of a complex Looyenga mixing model (Looyenga 1965; Wilhelms, 2000). The Looyenga model assumes firn to be a mixture of ice and air spheres with each a characteristic permittivity. To correct for the geometry of the measuring electrode, the free-air reading was used.

Comparison of the Looyenga density profile with that from the weighed firn core (bulk density) revealed a systematic difference of $3.4 \%$. This is probably chiefly caused by the error in bulk density determination. This is mainly related to the inaccuracy of the measured length of a core section and is estimated to be $2 \%$. The bulk density will mostly be lower than or equal to the real density due to loss of material. Correcting the DEP-derived densities for the bulk density, including material loss, yields an unexplained systematic overestimation of $1.4 \%$ for the DEP results, which is less than the given standard error of $2 \%$. However, the density error does not play a role in this study, in which our main interest was to locate peaks representing datable volcanic horizons. Nor does a systematic density error affect the accumulation rate variability, which is the main concern of the paper. The permittivity and conductivity were fitted in terms of density and conductivity of the ice, thus following local density changes in a core piece well.

To facilitate identification of peaks, the DEP signal caused by the seasonal cycle needed to be separated from low-frequency components and temperature effects. The DEP signal was corrected for variability in the temperature of each core section by an empirically derived Arrhenius equation (Paren, 1973; Glen and Paren, 1975). The activation energy used was found empirically by measuring one firn core at two different temperatures. Low-frequency noise can be caused by climatic trends, density effects or biogenic acidity (Mayewski and others, 1993; Karlöf and others, 2000). For this reason, the low-frequency components were removed by de-trending, wavelength high-pass filtering and smoothing of the signal (Karlöf and others, 2000). We used a first order Savitsky-Golay filter (Press and others, 1992) in the sample domain with samples every $250 \mathrm{~mm}$. Next, subtracting the mean and dividing by the standard deviation normalized the remaining signal. Peaks in the signal were, rather arbitrarily, assumed to be related to volcanic events whenever their amplitude was $>2 \sigma$ (Delmas and others, 1992; Mayewski and others, 1993; Zielinski and others, 1994).

The depth of an event's layer was considered to coincide with the signal peak's top. One could argue that the lower flank (i.e. the oldest flank) of the signal peak should be used to determine the depth of the related horizon because this signifies when the contaminated precipitation started. However, as it is subjective to determine where exactly the flank of a peak begins, we decided to take the top of the peak as the actual position of the peak. The depth of the top of the peak could then be determined accurately to within $1 \mathrm{~cm}$.

Figure 3 shows the result of the entire procedure as a function of depth (in metres water equivalent (m w.e.)) for the M150 and BAS cores. The depth scale of the BAS core is stretched so that peaks of the two records are more or less in 

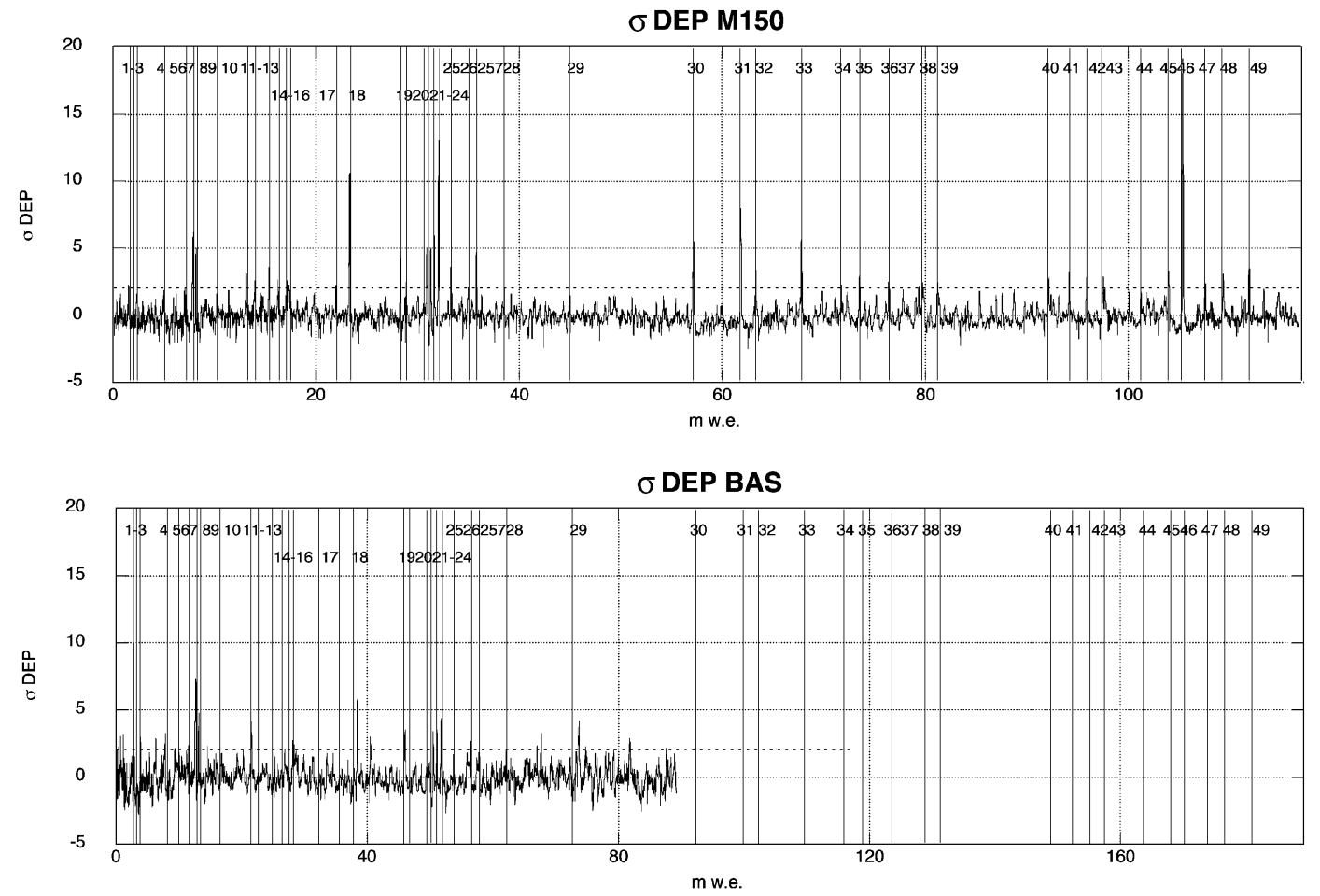

Fig. 3. Comparison of the processed normalized DEP data of M150 and BAS. Peaks are defined as having an amplitude greater than the threshold value of $2 \sigma$ which is indicated by the dotted line. All 50 peaks found in the normalized DEP datasets of the six firn cores are incorporated in the normalized DEP graph of both M150 and the BAS core. Black vertical lines indicate that the threshold was passed for both cores. Grey vertical lines indicate that the threshold was only passed for the M150 core.

line. Clearly, some but not all of the peaks show up in both records. Our " $2 \sigma$ criterion" resulted in the detection of 50 event horizons in the six firn cores. Of these events, 39 occurred in two or more cores and 11 were identified only once but are probably present in the other cores as well, with a smaller amplitude (Table 2). Figure 4 shows the entire dataset. The records are lined up such that peak 24 is in the same position for each record. The lower part of the M150 core is not shown, as it is the only one that covers this time-span.

\section{DATING FIRN GORES}

Annual-layer counting of the DEP data of M150 was not feasible due to the low accumulation rate (Table 1). Instead, we used a chronology based on comparing the DEP records with each other. Overlapping peaks are primarily dated by the chronology of CFA analyses (Sommer and others, 2000b; Traufetter and others in press) and the Dome $\mathrm{C}$ chronology (Schwander and others, 2001). Back to AD 1171, volcanic layers in Antarctic cores are well documented and there is little ambiguity about their age. Before AD 1171, the dates of peaks are less clear. First, we discuss the dating of the four published records $(\mathrm{CV}, \mathrm{B} 31-\mathrm{B} 33)$.

The CV firn core was dated assuming a (within 15\%) constant annual accumulation rate (Karlöf and others, 2000). An unidentified volcanic horizon in the firn core could then be expected to be within a certain age interval, and a candidate volcano was identified using the chronology of eruptions by Simkin and Siebert (1994).

Cores B31-B33 have been primarily dated by annuallayer counting based on CFA data and subsequent identification of a few prominent volcanic horizons: the Tambora (Indonesia) eruption of 1815, the Kuwae (Vanuatu) eruption of 1452 and an unknown volcanic event of 1259 (Som- mer and others, 2000a). The dating of B32 was revised later by annual-layer counting down to the bottom of the core (Traufetter and others, in press). The accuracy of the revised chronology is estimated to be \pm 1 year back to AD 1815, increasing to \pm 5 years at $\mathrm{AD} 1259$ and further back in time to \pm 23 years at AD 187 (Traufetter and others, in press).

The chronology of the Dome C core (not included in this paper) was established with a simple flow model and some tie points. Back to AD 1171, the chronology uses 14 welldocumented volcanic eruptions and the accuracy is estimated to be \pm 10 years (Schwander and others, 2001). For the period 7100 BP to AD 1171, the model was fitted to the Vostok GT4 scale by using a depth-to-depth relation based on a volcanic match. The model parameters were calibrated using 27 volcanic eruptions. The accuracy of the model chronology is 200 years for this period.

As mean annual accumulation rates of six firn cores from DML were being compared, identical events in different cores should have identical dates. The most accurate dating was available for cores B32 and B33, which have a CFAbased chronology. This time-scale was therefore adopted for all six cores. The chronology does not depend on any assumptions about an annual accumulation rate. For the period from the present back to AD 1108, the chronology of B32 was used (Sommer and others, 2000a; Traufetter and others, in press). Core B32 provides few DEP data before AD 1108, but the DEP data of B33 go back to AD 445. For this reason, we adopted the chronology of $\mathrm{B} 33$ for the period AD 1108-445 (Sommer and others, 2000a). Peaks dating back to events before AD 445 were only present in the DEP data of core M150. For AD 445 back to 452 BC, we used the chronology of Dome C. The use of several chronologies leads to some inconsistencies at the tie points, but was preferred over the Dome $\mathrm{C}$ chronology, which is available for the entire period. The Dome $\mathrm{G}$ chronology has an estimated 
Table 2. Overview of 50 volcanogenic peaks that pass the threshold value of $2 \sigma$ at least in one core. This is represented by a + sign in the columns. The number in the last column represents the number of cores in which a peak is larger than the $2 \sigma$ threshold value.VEI is the volcanic explosivity or dust veil index, which is a measure for the strength of an eruption. The superscript symbols indicate which time-scale was used for dating, as explained in the text. Question marks signify that it is uncertain which volcano caused the enhanced DEP levels

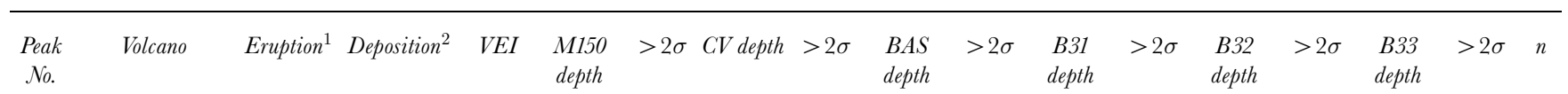
$\mathrm{AD}$
$\mathrm{AD}$
$\mathrm{m}$
$\mathrm{m}$
$\mathrm{m}$
$\mathrm{m}$
$\mathrm{m}$
$\mathrm{m}$

\begin{tabular}{|c|c|c|c|c|c|c|c|c|c|c|c|c|c|c|c|c|c|}
\hline $0^{*}$ & $\begin{array}{l}\text { Deception } \\
\text { Island }\end{array}$ & 1970 & & & & & 4.71 & + & & & & & & & & & 1 \\
\hline $1^{\dagger}$ & Agung & 1963 & 1964 & 4 & 4.69 & + & & & 6.40 & - & 5.48 & + & 5.92 & - & 4.34 & - & 2 \\
\hline $2^{\dagger}$ & unknown & 1959 & & & & & & & 7.18 & + & 6.37 & - & 6.77 & - & 5.02 & - & 1 \\
\hline $3^{\dagger}$ & Ambrym? & 1952 & & $4+$ & 6.77 & - & & & & & & & 8.05 & + & 5.54 & - & 1 \\
\hline $4^{\dagger}$ & Krakatau & 1883 & 1884 & 6 & 13.03 & - & 15.56 & + & 17.22 & + & 15.2 & + & 16.25 & + & 12.38 & - & 4 \\
\hline $5^{\dagger}$ & unknown & 1862 & & & 14.98 & - & 17.91 & + & 19.96 & + & 17.57 & - & 18.83 & - & 14.30 & - & 2 \\
\hline $6^{\dagger}$ & Coseguina & 1835 & 1835 & 5 & 17.22 & - & & & 23.20 & - & 20.65 & + & 21.75 & + & 16.49 & - & 2 \\
\hline $8^{\dagger}$ & Tambora & 1815 & 1816 & 7 & 18.84 & + & 22.87 & + & 25.62 & + & 22.64 & + & 23.87 & + & 18.05 & + & 6 \\
\hline $9^{\dagger}$ & unknown & 1809 & 1809 & & 19.36 & + & 23.60 & + & 26.43 & + & 23.44 & + & 24.51 & + & 18.64 & + & 6 \\
\hline $10^{\ddagger}$ & Peteroa/Ma- & 1762 & 1762 & $4 / 4$ & 23.23 & - & 28.38 & + & & & 28.41 & + & & & 22.34 & - & 2 \\
\hline $11^{\dagger}$ & $\begin{array}{l}\text { kian? Raoul? } \\
\text { unknown }\end{array}$ & 1695 & & & 28.42 & + & 34.60 & + & 39.19 & + & 35.44 & + & 35.9 & + & 27.28 & + & 6 \\
\hline $12^{\dagger}$ & Gamkonora & 1673 & 1676 & 5 & 29.88 & + & 36.36 & + & & & 37.38 & - & 37.83 & - & 28.77 & + & 3 \\
\hline $13^{\dagger}$ & $\begin{array}{l}\text { Awu/Deception } \\
\text { Isl/Long Island? }\end{array}$ & 1641 & 1641 & $5 / 6$ & 32.26 & + & 39.20 & + & 44.50 & - & 40.71 & + & 40.73 & + & 31.02 & + & 5 \\
\hline $15^{\dagger}$ & Huyanaputina & 1600 & 1601 & 6 & 35.18 & + & 42.45 & + & 48.39 & + & 44.56 & + & 44.36 & - & 33.91 & + & 5 \\
\hline $16^{\dagger}$ & Ruiz/Raung? & 1595 & 1596 & $4 / 5$ & 35.52 & + & 42.98 & + & 49.03 & - & 45.1 & + & 44.83 & + & 34.23 & + & 5 \\
\hline $17^{\dagger}$ & Billy Mitchell? & 1542 & 1542 & 6 & 39.57 & - & 47.14 & & & & 50.06 & & & & 37.91 & + & 1 \\
\hline $18^{\dagger}$ & Kuwae & 1452 & 1453 & 6 & 45.04 & + & 53.80 & + & 61.78 & + & 57.89 & + & 56.84 & + & 43.35 & + & 6 \\
\hline $19^{\dagger}$ & El Chichón? & 1343 & 1343 & $\geq 4$ & 52.59 & + & 62.80 & + & 71.25 & + & 67.53 & + & 66.02 & + & 50.51 & + & 6 \\
\hline $20^{\dagger}$ & unknown & 1334 & & & 53.34 & + & & & & & & & & & & & 1 \\
\hline $21^{\dagger}$ & unknown & 1286 & 1285 & 5 & 56.34 & + & 67.57 & + & 76.05 & - & 72.03 & + & 70.55 & + & 54.13 & + & 5 \\
\hline $22^{\dagger}$ & Tarawera? & 1279 & 1278 & & 56.92 & + & 68.37 & + & 76.77 & + & 72.78 & + & 71.26 & + & 54.62 & + & 6 \\
\hline $23^{\dagger}$ & Lolobau? & 1269 & 1269 & 4 & 57.38 & + & 68.98 & + & 77.44 & + & 73.37 & + & 71.81 & + & 55.08 & + & 6 \\
\hline $24^{\dagger}$ & El Chichón & 1259 & 1258 & & 57.96 & + & 69.79 & + & 78.28 & + & 74.14 & + & 72.57 & + & 55.69 & + & 6 \\
\hline $25^{\dagger}$ & unknown & 1231 & 1228 & & 59.75 & + & 72.17 & + & 80.68 & - & 76.20 & + & 74.72 & + & 57.32 & + & 5 \\
\hline $26^{\dagger}$ & unknown & 1190 & 1188 & & 62.12 & + & 75.43 & - & 83.92 & + & 78.90 & - & 77.71 & + & 59.68 & + & 4 \\
\hline $27^{\dagger}$ & Billy Mitchell? & 1171 & 1172 & $5+$ & 63.24 & + & 77.00 & + & 85.52 & + & 80.23 & - & 79.21 & - & 60.96 & - & 3 \\
\hline $28^{\dagger}$ & $\begin{array}{c}\text { Guagua Pi- } \\
\text { chincha? }\end{array}$ & 1108 & 1108 & $\geq 4$ & 67.01 & + & & + & & & & & 83.55 & - & & & 2 \\
\hline $29^{\dagger}$ & $\begin{array}{l}\text { Pelee?/Daka- } \\
\text { taua? }\end{array}$ & 965 & 961 & $\geq 4$ & 75.62 & - & & - & 104.15 & & & & & & 73.12 & + & 1 \\
\hline $31^{\ddagger}$ & unknown & 578 & 578 & & 96.80 & + & 118.68 & + & & & & & 120.59 & - & 93.77 & + & 3 \\
\hline $32^{\ddagger}$ & unknown & 543 & 542 & & 98.61 & + & & & & & & & 122.91 & + & 95.57 & + & 3 \\
\hline $33^{\ddagger}$ & Ilopango? & 445 & 442 & 6 & 103.95 & & & & & & & & 129.71 & - & 100.79 & + & 2 \\
\hline $34^{\dagger \dagger}$ & - & & & & 108.64 & + & & & & & & & & & & & $\overrightarrow{1}$ \\
\hline $35^{\ddagger}$ & unknown & 311 & & & 110.72 & + & & & & & & & & & & & 1 \\
\hline $36^{\ddagger}$ & Ambrym? & 244 & & $6+$ & 114.10 & + & & & & & & & & & & & 1 \\
\hline $37^{\ddagger}$ & Taupo? & 177 & 187 & 6 & 117.54 & + & & & & & & & & & & & 1 \\
\hline $38^{\dagger \dagger}$ & - & & & & 117.96 & + & & & & & & & & & & & 1 \\
\hline $39^{\ddagger}$ & unknown & 132 & & & 119.69 & + & & & & & & & & & & & 1 \\
\hline $40^{\dagger \dagger}$ & - & & & & 132.16 & + & & & & & & & & & & & 1 \\
\hline $41^{* *}$ & unknown & -114 & & & 134.39 & + & & & & & & & & & & & 1 \\
\hline $42^{* *}$ & unknown & -153 & & & 136.35 & + & & & & & & & & & & & 1 \\
\hline $43^{* *}$ & unknown & -188 & & & 138.21 & + & & & & & & & & & & & 1 \\
\hline $44^{* *}$ & unknown & -273 & & & 142.37 & + & & & & & & & & & & & 1 \\
\hline $45^{* *}$ & unknown & -331 & & & 145.44 & + & & & & & & & & & & & 1 \\
\hline $46^{* *}$ & unknown & -364 & & & 147.00 & + & & & & & & & & & & & 1 \\
\hline $47^{\dagger \dagger}$ & - & & & & 149.52 & + & & & & & & & & & & & 1 \\
\hline $48^{* *}$ & unknown & -452 & & & 151.47 & + & & & & & & & & & & & 1 \\
\hline $49^{\dagger \dagger}$ & - & & & & 154.36 & + & & & & & & & & & & & 1 \\
\hline
\end{tabular}

${ }^{1}$ Date from Simkin and Siebert (1994).

${ }^{2}$ Date from Traufetter and others (in press).

*Time-scale of CV core drilled in 1997/98 (Karlöf and others, 2000).

${ }^{\dagger}$ Time-scale of B32 (Sommer and others, 2000a).

${ }^{\ddagger}$ Time-scale of B33 (Sommer and others, 2000a).

*** Time-scale of Dome C core drilled in 1998/99 (Schwander and others, 2001).

${ }^{\dagger \dagger}$ Only in M150; no date available. 


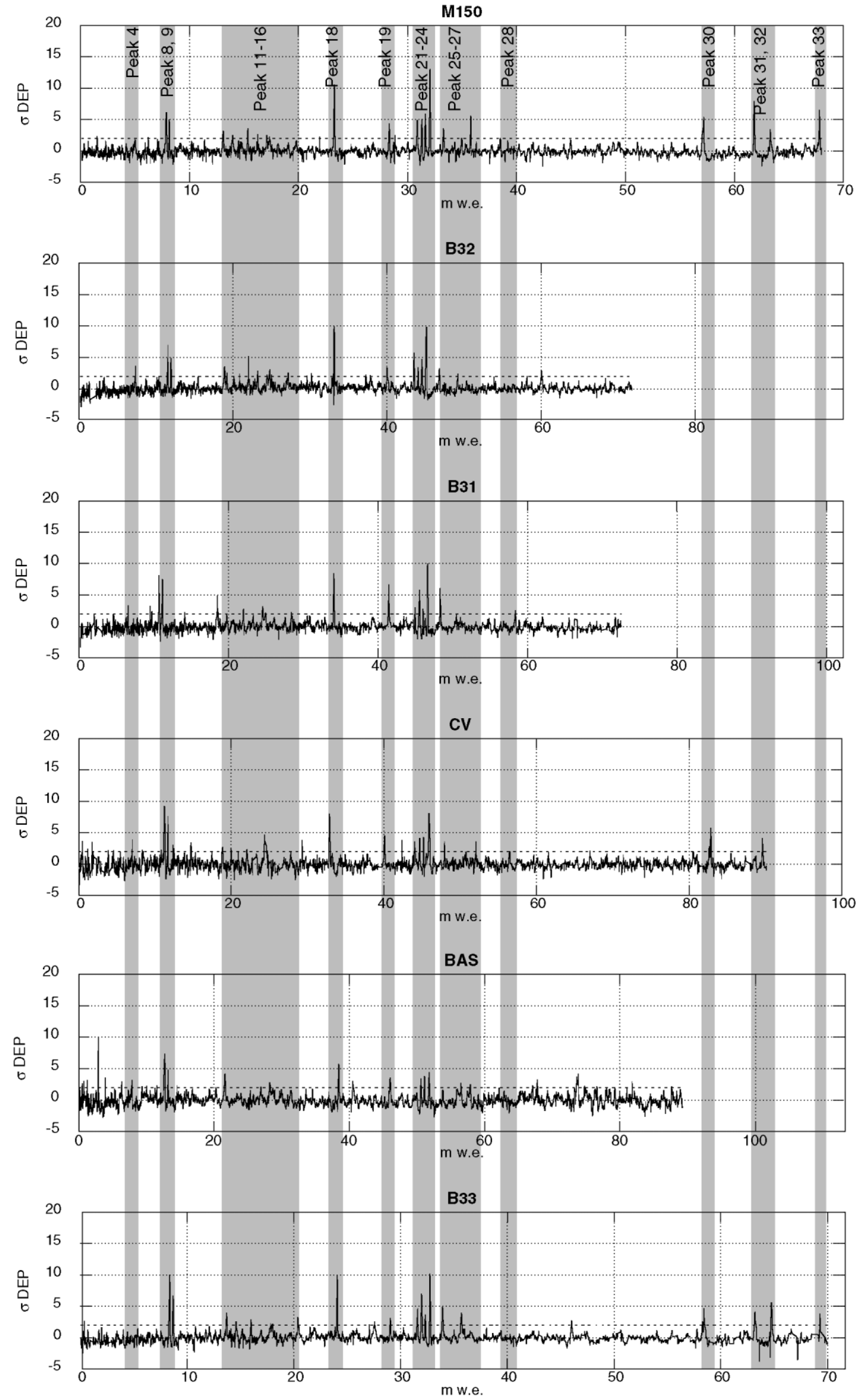

Fig. 4. Overview of the processed normalized DEP data of the six firn cores from AD 445 to present. The AD 1259 eruption (peak $24)$ is lined up in all DEP profiles, so the $m$ w.e. scale (horizontal) varies from core to core. Cores are displayed from the top to the bottom in east-west direction. Grey bands mark peaks from strong eruptions. 

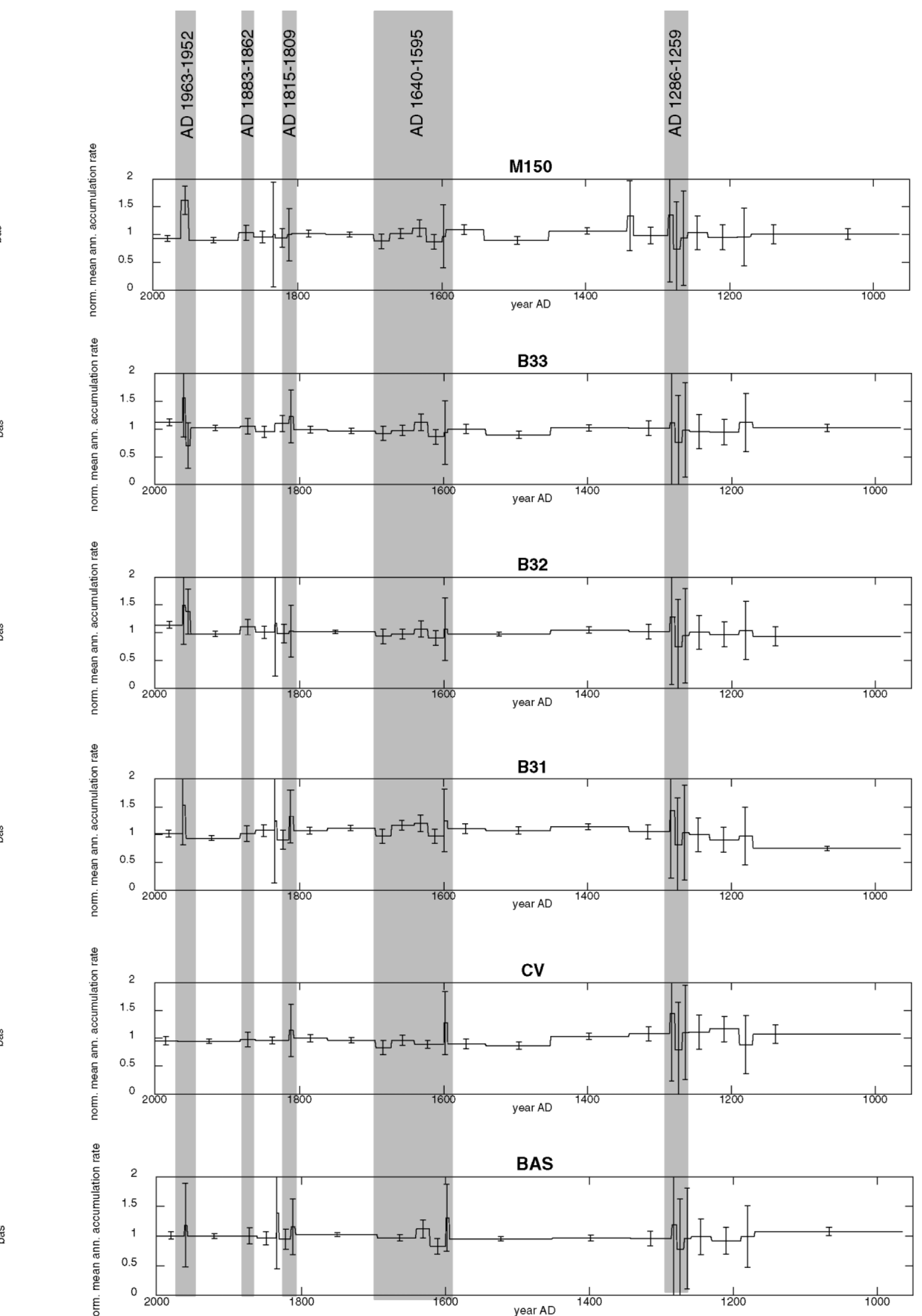

Fig. 5. Overview of the normalized mean annual accumulation rates for the six medium-length ice cores, including error bars over the last 1000 years. The AD 1259 eruption (peak 24) is lined up in all DEP profiles, so the age scale (horizontal) varies from core to core. Grey bands represent time periods with strong eruptions.

accuracy of 10 years (Schwander and others, 2001), not as good as the CFA-based chronology of B32 and B33, which has a decreasing accuracy of $1-5$ years for the last 800 years (Sommer and others, 2000a; Traufetter and others, in press).

As a by-product of the comparison of the DEP records of the six cores, we attempted to identify the peaks observed in our dataset that had not yet been assigned to specific volcanic eruptions. This procedure and its results are described in Appendix A.

Results of this procedure indicated some new candidates 


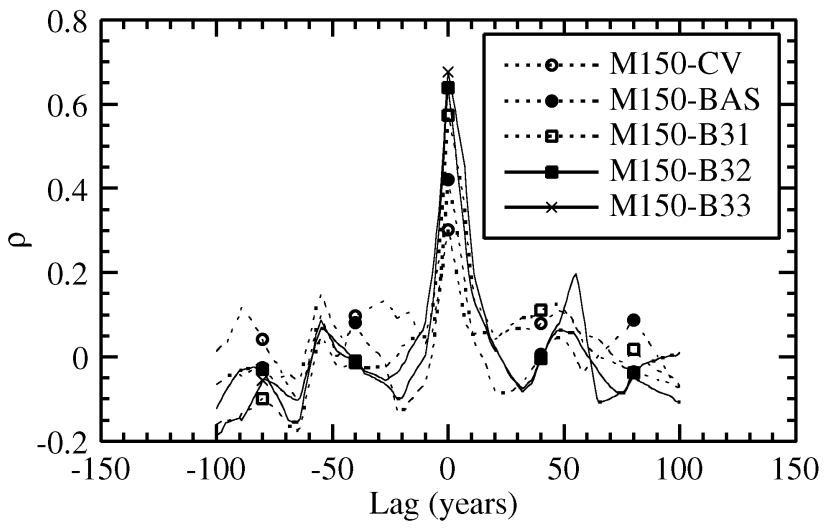

Fig. 6. Cross-correlation coefficients as a function of time lag relative to the $M 150$ record.

for volcanic horizons. As mentioned in the Appendix, identification was performed purely on the strength of the eruption and the geographic location of the volcano. As no chemical analyses of particulates have been carried out on these volcanic horizons, results should be interpreted with care, as the volcanic explosivity index (VEI) is a measure of the strength of the outburst and not of the strength of a
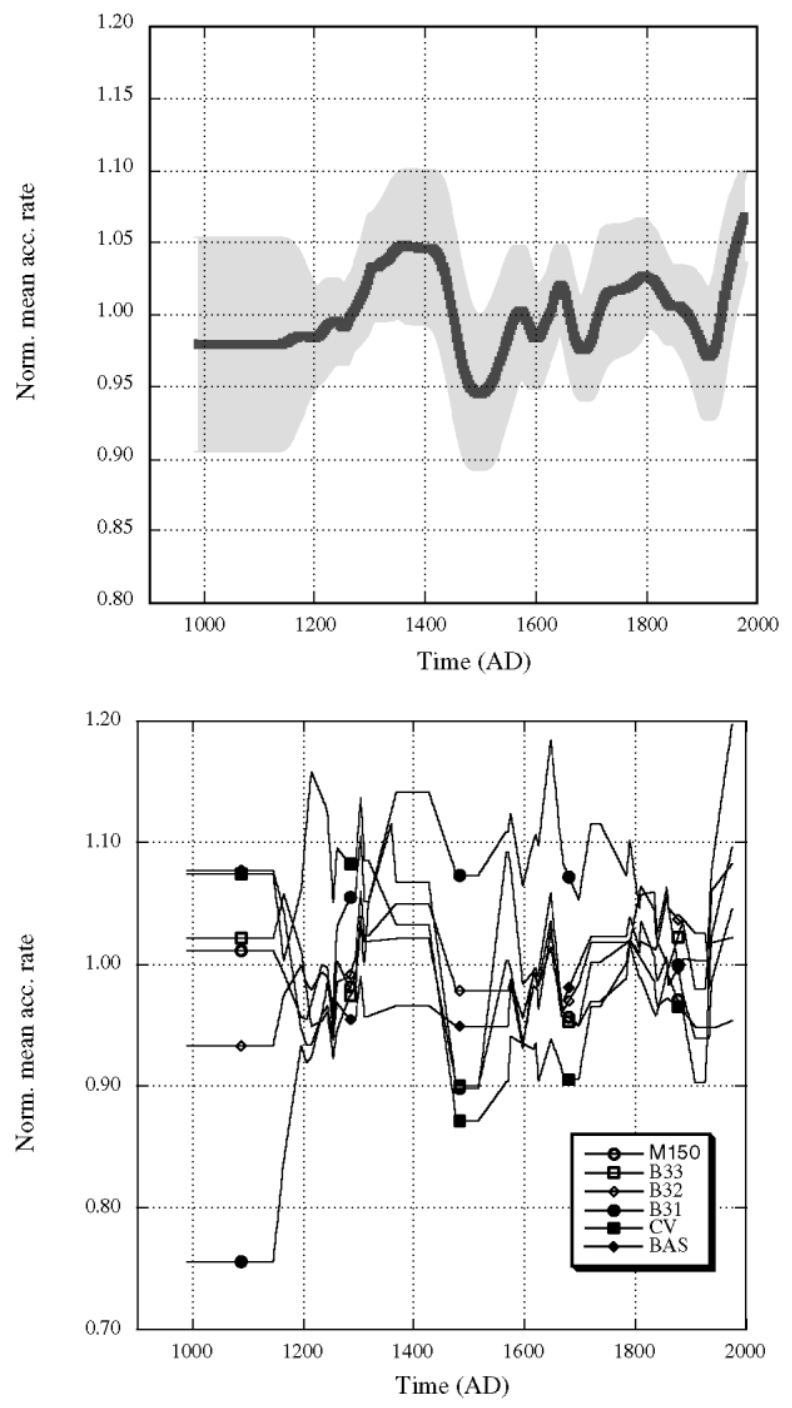

Fig. 7. Mean annual accumulation rate of the six firn cores, averaged with a running mean with a period of 50 years. The grey shaded band indicates $1 \sigma$ uncertainty.
DEP peak which is often dominated by the sulphate load. As new candidates for unidentified eruptions we summarize:

Billy Mitchell, Papua New Guinea, for the eruption of AD 1542 for which evidence was observed in three firn cores; and El Chichón, Mexico, for the eruption in AD 1343 which produced horizons in all firn cores.

Tarawera, New Zealand, and Lolobau, Papua New Guinea, could have caused one of the horizons dated as AD 1279, 1269 and 1259.

The AD 1171 eruption, observed in the DEP data in three of the six cores (and in the CFA data of the other three cores), could have been caused by an eruption of Billy Mitchell.

Contrary to Karlöf and others (2000), we suggest that Rabaul, Papua New Guinea, is a candidate for the AD 688 eruption but not for the AD 540 eruption.

The Ilopango (El Salvador) eruption could be the source of the peak dated at around AD 445, which was observed in both cores that reach back that far in time (see Simkin and Siebert, 1994).

A possible source for an eruption at AD 177 is Taupo, New Zealand.

The clear volcanic horizon at $147 \mathrm{~m}$ in core M150 and dated around $452 \mathrm{BC}$ has not been identified. The eruption must have been strong, as it shows up clearly in the DEP data of Dome $\mathrm{C}$, which is some $2600 \mathrm{~km}$ away from site M.

\section{VARIABILITY OF ACGUMULATION RATES}

Having dated the cores with one time-scale, we calculated the mean annual accumulation rate between the dated events and compared the mean annual accumulation rate of the six cores as a function of time. The joint accumulation record of each of the six cores covers the period AD 9651998. The mean annual accumulation rate simply follows from the datum stratum, with the mw.e. depth of the core section above the dated horizon divided by the time-span (Karlöf and others, 2000). The effect of layer thinning due to strain was ignored, as the length of the cores never exceeds $10 \%$ of the total ice thickness. The resulting accumulation rates were normalized by dividing by the average accumulation rate of a core over the period studied here (see Fig. 5).

As some volcanic horizons are present in a relatively small section (representing a short time-span), the mean annual accumulation rate might vary considerably over these time-spans due to the high interannual variability of accumulation. As a result, the error in accumulation rate is greatest in these short time intervals. The magnitude of the accumulation error in Figure 5 is determined by the accuracy of the dated event and of the determination of the bulk weight of the ice core (always 2\%). The dating error is estimated to increase from \pm 2 years, for the younger events for which the CFA time-scale was used, to 10 years for the year 965. As a result, the accumulation-rate error is greater for shorter time intervals because the total error is then determined by the dating uncertainty. For longer time-spans, the error is dominated by the error in the density, which is relatively small.

In order to track and exclude errors in the dating of in- 

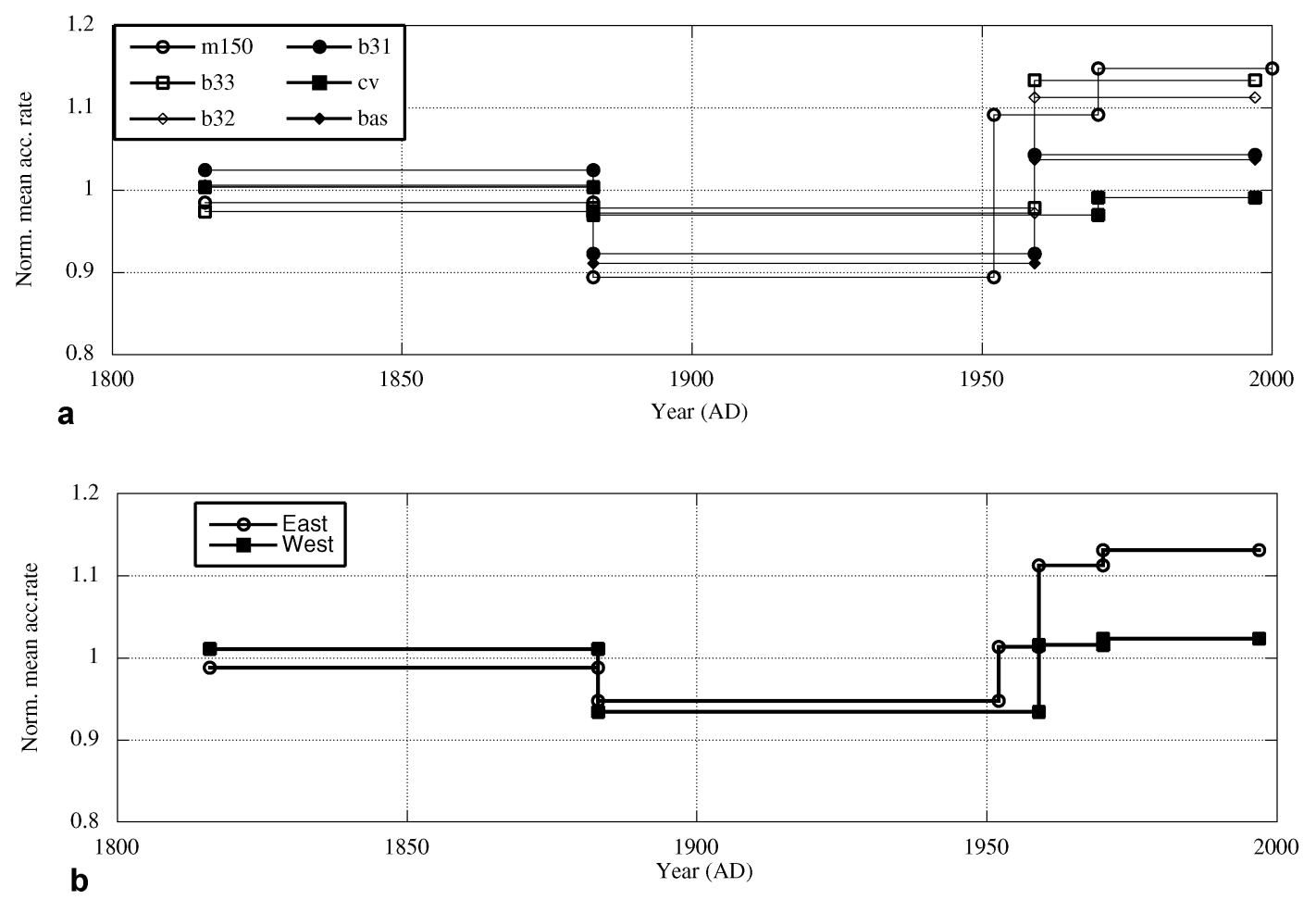

Fig. 8. (a) Mean annual accumulation rate of the six cores for the last 200 years. Markers are the Tambora eruption and Krakatau in the 19th century and an eruption somewhere in the 20th century. The latter is not always the same for the different cores. (b) Mean accumulation rate over western (BAS, CV, B31) and eastern (B32, B33, M150) DML.

dividual DEP records, we calculated the cross-correlation coefficients between the six cores, 15 cross-correlation coefficients in total. Results for the cross-correlation coefficients as a function of time lag are shown in Figure 6, where all other records are compared with the M150 record. The highest cross-correlation coefficients are found for a time lag of 0 . This means that there are no severe dating errors due to missing layers, erosion or other causes.

Five periods with local maxima and minima can be recognized in all cores (indicated by grey bands in Fig. 5). Small differences are caused by events that were not present in all cores. To eliminate these short-period variations, the accumulation rates were averaged by calculating the running mean over 50 year periods. Since the standard deviations of the records are comparable, no stacking or standardization with the variance is needed, but simple averaging is sufficient. Figure $7 \mathrm{a}$ and $\mathrm{b}$ present the results for the mean and for the individual records respectively. The variation on time-scales of 50 years is only about $5 \%$. The six cores reveal only weak overall trends that are not statistically significant. Linear correlation coefficients for the 50 year running mean of the accumulation are also not significant. Figure 7 displays a local maximum in the firn accumulation rate around $\mathrm{AD} 1800$, followed by a local minimum around AD 1900 and an increase over the early 20th century. There are also local maxima around AD 1650 and 1580. Most pronounced is the local minimum around AD 1500, clearly present in all datasets, and the maximum at the end of the 14th century.

Cross-correlation coefficients are highest for cores M150, B33 and B32, indicating that these records show similar variations throughout the time period considered, although the amplitude of the variation in M150 is slightly larger than in B33 and B32. These three cores are from the three highest locations on the plateau, and apparently experienced similar climatological conditions. Cores B31, GV and BAS do not fit this general picture. They are situated on the western "slope" of the ice sheet, with larger temporal and spatial fluctuations. The differences in accumulation rate of these cores are apparently more localized (Fig. 5). In the GV core, three main periods can be recognized, AD 1100-1450, 1450-1700 and 1700-present. The period AD 1100-1450 represents a maximum in average accumulation; for this period, the values are higher than for any of the other cores. From AD 1450 to 1700, there is a minimum in accumulation rate, and from $\mathrm{AD} 1700$ to present the accumulation rate is close to average except for a maximum around AD 1800, which was found for all cores. The BAS core shows no clear separate periods from AD 1100 to present. There has been a gentle increase in accumulation rate over time, again with a local maximum around AD 1800. The accumulation of core B31 is different again. Here, a weak significant decrease in accumulation is observed from around $\mathrm{AD} 1300$ to around $\mathrm{AD} 1900$. The local maximum around $\mathrm{AD} 1800$ is also observed, and the minimum around AD 1500 also found for several other cores. The low value for AD 965-1171, which is not observed in any of the other cores, is probably due to local changes in topography and is discussed by Oerter and others (in press).

Despite the limited temporal resolution, we considered the last two centuries in more detail. To obtain an overview of the last 200 years we selected a few characteristic events for all cores. We used the Tambora and Krakatau (Indonesia) eruptions to characterize the 19th-century accumulation. The early 20 th century is characterized by using the Krakatau eruption and a DEP peak as early as possible in the second half of the 20th century. The latter part of the 20 th century is finally characterized by this peak and the surface level. Results of this subdivision in about 60 year periods are presented in Figure 8. It can be observed that 
the early 20th century is relatively dry whereas the second half of the 20th century is wetter for some cores. Based on the high cross-correlation coefficients presented in Figure 6, we divided the six cores into two groups, one representing western DML (BAS, GV and B31) and the other eastern DML (B32, B33, M150). Results of this subdivision are shown in Figure 8b. It can be observed that eastern DML, in particular, experiences increased accumulation.

\section{DISGUSSION AND CONGLUSIONS}

Our main objective was to achieve an overview of the mean annual accumulation record for DML derived from the DEP data of these cores. For this purpose, we adopted the same time-scale for all cores, which was mainly based on the subannual resolved CFA analyses. The mean annual accumulation records show no significant trend, but coherent fluctuations can be observed. The lack of trend is in agreement with earlier studies by Karlöf and others (2000) and Sommer and others (2000a). Previous firn accumulation results based on other techniques, for the same period at the South Pole, did not show climatically significant changes either (Van der Veen and others, 1999). Oerter and others (1999) and Graf and others (2002) presented temporal variations for the last two centuries in central DML, based on DEP, tritium and stable-isotope measurements. Their results indicate a decrease in firn accumulation during the 19th century followed by an increase over the early 20 th century and thereafter, stabilization at a level similar to that of the early 19th century. The Berkner Island (West Antarctica) records presented by Mulvaney and others (2002a) only show increased accumulation rates for the Northern Dome and no decreased levels earlier in the 19th century. Stenni and others (2002) published an 800 year record for Talos Dome, East Antarctica, with an opposite signal for the early 20th century and continued enhanced accumulation during recent decades. Karlöf and others (2000) published a 1500 year record from western DML indicating no overall trend in firn accumulation rate, except a decrease of $8 \%$ between AD 1452 and 1641. Sommer and others (2000a) presented results for the B31-B33 cores that also revealed no overall trend for the period AD 1100-1996.

In all six cores of the present study, covering a larger part of DML than previous work by Graf and others (2002), there are local minima around AD 1500 and 1680. The minimum around AD 1500 is also observed by Stenni and others (2002) for Talos Dome. All cores also display a local maximum around AD 1800 followed by a minimum around AD 1900. The joint accumulation records of cores B32, B33 and M150 show the highest cross-correlation coefficients. This is most likely due to the similarity in the climate conditions experienced on the high plateau of central DML. Surprisingly little coherence is found for the accumulation records of cores BAS, CV and B31, which were retrieved from the western slope of the ice sheet in DML. Apparently, the temporal and spatial variation in accumulation is larger on the western slope of the ice cap than on the eastern plateau. Although no general trend is found in the six cores, the strongest increase in the mean annual firn accumulation rate is observed in the early 20th century. Due to the absence of distinct volcanic horizons in the late-20thcentury sections, the present study can only be used with care for the second half of the 20th century. Based on Figure $8 \mathrm{~b}$ we conclude that only in eastern DML is accumulation significantly increased in the second half of the 20th century with respect to the long-term mean accumulation rate.

\section{ACKNOWLEDGEMENTS}

We acknowledge the logistic personnel involved in the expeditions. We thank all members of the NARE 2000/01 expedition, whose team spirit made this expedition successful. We are also grateful to O. Jalving, M. Portanger, J. Brand and E.-J. de Jong, whose efforts resulted in the creation and upgrade of the Utrecht DEP instrument and drill, and to J. Kohler and A. van Dijk for constructive discussions. We are grateful to E. Steig and J. Turner for their constructive reviews. This work is a contribution to the European Project for Ice Coring in Antarctica (EPICA), a joint European Science Foundation/European Commission scientific programme, funded by the European Commission under the Environment and Climate Programme and by national contributions from Belgium, Denmark, France, Germany, Italy, The Netherlands, Norway, Sweden, Switzerland and the United Kingdom. This is EPICA Publication No. 97. Additional funding was obtained from the Netherlands Antarctic Programme of the Netherlands Organization for Scientific Research (NWO).

\section{REFERENCES}

Delmas, R. J., M. Legrand, A. J. Aristarain and F. Zanolini. 1985. Volcanic deposits in Antarctic snow and ice. 7. Geophys. Res., 90 (D7), 12,901-12,920.

Delmas, R. J., S. Kirchner, J. M. Palais and J.-R. Petit. 1992. 1000 years of explosive volcanism recorded at the South Pole. Tellus B, 44(4), 335-350.

Dull, R. A., J. R. Southon and S. Payson. 2001. Volcanism, ecology and culture: a reassessment of the volcano Ilopango TBJ eruption in the southern Maya realm. 7. Lat. Amer. Antiq., 12(1), 25-44.

Glen, J.W. and J. G. Paren. 1975. The electrical properties of snow and ice. 7. Glaciol., 15 (73), 15-38.

Graf, W. and 6 others. 2002. Stable-isotope records from Dronning Maud Land, Antarctica. Ann. Glaciol., 35, 195-201.

Karlöf, L. and 13 others. 2000. A 1500 year record of accumulation at Amundsenisen, western Dronning Maud Land, Antarctica, derived from electrical and radioactive measurements on a $120 \mathrm{~m}$ ice core. F. Geophys. Res., 105 (D10), 12,471-12,483.

Looyenga, H. 1965. Dielectric constant of heterogeneous mixtures. Physica, 31 (3), 401-406

Mayewski, P. A. and 8 others. 1993. Greenland ice core "signal" characteristics: an expanded view of climate change. 7. Geophys. Res., 98(D7), $12,839-12,847$

Moore, J. C. and J. G. Paren. 1987. A new technique for dielectric logging of Antarctic ice cores. F. Phys. (Paris) 48, Colloq. Cl, 155-160. (Supplément au 3.)

Moore, J. C., E.W. Wolff, H. B. Clausen and C. U. Hammer. 1992. The chemical basis for the electrical stratigraphy of ice. 7. Geophys. Res., 97(B2), 1887-1896.

Mulvaney, R. and 8 others. 2002a. 1000 year ice-core records from Berkner Island, Antarctica. Ann. Glaciol., 35, 45-51.

Mulvaney, R., S. Bremner, A. Tait and N. Audley. 2002b. A medium-depth ice core drill. Nat. Inst. Polar Res. Mem., Special Issue, 56, 82-90. (Ice Drilling Technology 2000.)

Oerter, H., W. Graf, F. Wilhelms, A. Minikin and H. Miller. 1999. Accumulation studies on Amundsenisen, Dronning Maud Land, by means of tritium, dielectric profiling and stable-isotope measurements: first results from the 1995-96 and 1996-97 field seasons. Ann. Glaciol., 29, 1-9.

Oerter, H. and 6 others. 2000. Accumulation rates in Dronning Maud Land, Antarctica, as revealed by dielectric-profiling measurements of shallow firn cores. Ann. Glaciol., 30, 27-34.

Oerter, H., W. Graf, H. Meyer and F. Wilhelms. In press. The EPICA ice core, Dronning Maud Land: first results from stable-isotope measurements. Ann. Glaciol.

Palais, J. M., S. Kirchner and R. J. Delmas. 1990. Identification of some global volcanic horizons by major element analysis of fine ash in Antarctic ice. Ann. Glaciol., 14, 216-220.

Paren, J. G. 1973. The electrical behavior of polar glaciers. In Whalley, E., 
S. J. Jones and L.W. Gold, eds. Physics and chemistry of ice. Ottawa, Ont., Royal Society of Canada, 262-267.

Press, W. H., S. A. Teukolsky, W.T. Vetterling and B. P. Flannery. 1992. Numerical recipes in C: the art of scientific computing. Second edition. Cambridge, Cambridge University Press.

Schwander, J., J. Jouzel, C. U. Hammer, J. R. Petit, R. Udisti and E. Wolff. 2001. A tentative chronology for the EPICA Dome Concordia ice core. Geophys. Res. Lett., 28 (22), 4243-4246.

Simkin, T. and L. Siebert. 1994. Volcanoes of the world. Second edition. Tucson, AZ, Geoscience Press.

Sommer, S. and 9 others. 2000a. Glacio-chemical study spanning the past $2 \mathrm{kyr}$ on three ice cores from Dronning Maud Land, Antarctica. 1. Annually resolved accumulation rates. F. Geophys. Res., 105(D24), 29,411-29,421.

Sommer, S., D. Wagenbach, R. Mulvaney and H. Fischer. 2000b. Glaciochemical study spanning the past $2 \mathrm{kyr}$ on three ice cores from Dronning Maud Land, Antarctica. 2. Seasonally resolved chemical records. 7. Geophys. Res., 105(D24), 29,423-29,433.

Stenni, B. and 6 others. 2002. Eight centuries of volcanic signal and climate change at Talos Dome (East Antarctica). 7. Geophys. Res., 107(D9). (10.1029/2000JD000317.)

Stuiver, M., P. J. Reimer and T. F. Braziunas. 1998a. High-precision radiocarbon age calibration for terrestrial and marine samples. Radiocarbon, $40(3), 1127-1151$.

Stuiver, M. and 9 others. 1998b. INTERCAL98 radiocarbon age calibration, 24,000-0 cal BP. Radiocarbon, 40 (3), 1041-1083.

Traufetter, F., H. Oerter, H. Fischer, R. Weller and H. Miller. In press. Spatio-temporal variability in volcanic sulphate deposition over the past $2 \mathrm{kyr}$ in ice cores from Amundsenisen, Dronning Maud Land, Antarctica. F. Glaciol.

Van den Broeke, M. R. and 6 others. 1999. Climate variables along a traverse line in Dronning Maud Land, East Antarctica. F. Glaciol., 45(150), 295-302.

Van der Veen, C. J., E. Mosley-Thompson, A. Gow and B. G. Mark. 1999. Accumulation at South Pole: comparison of two 900-year records. 7. Geophys. Res., 104(D24), 31,067-31,076.

Wilhelms, F. 1996. Leitfahigkeits- und Dichtemessung an Eisbohrkernen [Measuring the conductivity and density of ice cores.]. Ber. Polarforsch. 191. [In German with English abstract.]

Wilhelms, F. 2000. Messung dielektrischer Eigenschaften polarer Eiskerne [Measuring the dielectric properties of polar ice cores.]. Ber. Polarforsch./ Rep. Pol. Res. 367, 1-171. [In German.]

Wilhelms, F., J. Kipfstuhl, H. Miller, K. Heinloth and J. Firestone. 1998. Precise dielectric profiling of ice cores: a new device with improved guarding and its theory. F. Glaciol., 44(146), 171-174.

Winther, J.-G. and 10 others. 2002. European Project for Ice Coring in Antarctica (EPICA) - Nordic traverse in 2000/01. In Winther, J.-G., ed. Report of the Norwegian Antarctic Research Fxpedition 2000-2001. Oslo, Norsh Polarinstitutt, 18-29. (Rapportserie 120.)

Zielinski, G. A. and 8 others. 1994. Record of volcanism since 7000 B.C. from the GISP2 Greenland ice core and implications for the volcano-climate system. Science, 264(5161), 948-952.

\section{APPENDIX}

\section{IDENTIFIGATION OF VOLGANIC HORIZONS}

From the present back to AD 1171, most volcanic eruptions are historically well documented:

1815: the clear horizon of the Tambora eruption

1809: unidentified event

1452: the strong signal of Kuwae

1259: a strong eruption signal identified by some as El Chichón (Palais and others, 1990; Delmas and others, 1992). The event is the oldest in a short series of four volcanic eruptions, dated AD 1286, 1279, 1269 and 1259. The 1259 event is preceded by three strong events, in AD 1231, 1190 and 1171. The 1171 event does not show up in the DEP data of cores B31-B33, but does show up in the CFA data.

We used Simkin and Siebert's (1994) chronology of eruptions to assign volcanic events that have been dated but not yet identified. This chronology uses the VEI as a measure for the strength of the eruption on a logarithmic scale. We made the identification purely on the strength of the eruption and the latitude of the geographic location of the volcano (Delmas and others, 1985; Karlöf and others, 2000). No geochemical analyses were carried out on these volcanic horizons, and our results should be interpreted with care as the VEI is not a measure of the strength of a DEP peak, which is often dominated by the sulphate load.

We considered (l) eruptions with VEI $\geq 4$ between $20^{\circ} \mathrm{N}$ and $20^{\circ} \mathrm{S}$; (2) eruptions with VEI $\geq 4$ south of $20^{\circ} \mathrm{S}$; and (3) Antarctic and sub-Antarctic eruptions having only local impact. It was not obvious to which volcanic eruption some peaks were related, as indicated by question marks in Table 2. We used the database of Stuiver and others (1998a, b) to calibrate volcanic eruptions listed by Simkin and Siebert (1994) which had been dated with so-called uncorrected radiocarbon data. This revealed interesting possibilities for eruptions that have not yet been assigned to a specific volcano in the literature, as far as we know. The dates of the events, their sources, the radiocarbon dates and calibrated possible sources are listed in Table 3. In the following paragraphs, we discuss important volcanic horizons of the eruptions as numbered in Figure 3.

For peaks 1-3 (Fig. 3), the first clearly visible eruption is Agung, Indonesia, in 1963, detectable in M150 and B31 as an event. The peak is visible in B33 but does not meet our $2 \sigma$ criterion (see Table 2). Peaks 2 and 3 are unknown events in 1952 and 1959. A possible source for peak 3 is an eruption of Ambrym, Vanuatu, in 1951. Note that the Pinatubo (Philippines) eruption of 1991 does not show up in M150 and B31-B33, due to bad core quality at the top. However, for the locations of B31-B33 it was identified in snow pits (Traufetter and others, in press).

Peaks 21-24 were dated at AD 1286, 1279, 1269 and 1259. The oldest one, peak 24, has been suggested to represent a volcanic layer of El Chichón, based on a geochemical study of ash particles (Palais and others, 1990). According to Delmas and others (1992), the sources of peaks 22 and 23 are probably restricted to the Southern Hemisphere. Peak 23 is dated at AD 1269. The Lolobau eruption, radiocarbon-dated as $802 \mathrm{BP}$, is a possibility for peak 23. After calibration, the $2 \sigma$ interval is AD 1188 (1254) 1281 (Table 3). (The year in parentheses is the most likely date; the other years are the asymmetrical $1 \sigma$ and $2 \sigma$ confidence intervals.) A possible candidate for peak 22 or 21, dated AD 1279 or 1286, is the Tarawera eruption, radiocarbon-dated at 724 BP. Calibration of this radiocarbon date produced a $2 \sigma$ interval of AD 1267 (1283) 1297.

The year assigned to peak 27 is AD 1171. A global event has been dated at around AD 1177 by Schwander and others (Delmas and others, 1992; Schwander and others, 2001) and is likely to be the same event as peak 27. It shows up in three of the six DML cores. A possible source is the radiocarbondated eruption of Billy Mitchell at 870 BP. Calibrating this date yields a $2 \sigma$ interval AD $1154(1166,1188) 1236$. This peak shows up in the nss-conductivity profile of cores B31-B33, but not in the DEP results (Sommer and others 2000a, table 2). It was recognized in the sulphate record of B32 and B31 and dated by Traufetter and others (in press) at AD $1172 \pm 6$.

With peaks 30-33, the core chronologies of cores CV, B32, B33 start to deviate. Peak 30 is clearly recognizable in cores CV, B33 and M150 as a double peak (see Fig. 4). Cores BAS, B31 and B32 do not contain DEP data for this period. 
Table 3. Dated eruptions in core M150 with radiocarbon-calibrated volcanic eruptions as a possible source*

\begin{tabular}{|c|c|c|c|c|c|c|c|}
\hline \multirow[t]{2}{*}{ Peak } & Date & \multirow[t]{2}{*}{ Volcano } & \multirow[t]{2}{*}{$\begin{array}{l}\text { Radiocarbon-dated } \\
\text { alternative }\end{array}$} & \multirow{2}{*}{$\begin{array}{l}\text { Simkin date* } \\
\text { вР }\end{array}$} & \multirow{2}{*}{$\begin{array}{c}\text { Calibrated radiocarbon } \\
\text { dates } \\
\mathrm{AD}\end{array}$} & \multirow[t]{2}{*}{$2 \sigma$ confidence interval } & \multirow[t]{2}{*}{$V E I$} \\
\hline & $\mathrm{AD}$ & & & & & & \\
\hline & 2001 & & & & & & \\
\hline 0 & 1970 & Deception Isl. & & & & & \\
\hline 1 & 1963 & Agung & & & & & \\
\hline 2 & 1959 & unknown & & & & & \\
\hline 3 & 1952 & Ambrym? & & & & & \\
\hline 4 & 1883 & Krakatau & & & & & \\
\hline 5 & 1862 & unknown & & & & & \\
\hline 6 & 1835 & Coseguina & & & & & \\
\hline 7 & 1832 & unknown & & & & & \\
\hline 8 & 1815 & Tambora & & & & & \\
\hline 9 & 1809 & unknown & & & & & \\
\hline 10 & 1762 & Peteroa/Makian? & Raoul & 200 & $1668,1782,1795$ & $1637-1950$ & 4 \\
\hline 11 & 1695 & unknown & & & & & \\
\hline 12 & 1673 & Gamkonora & & & & & \\
\hline 13 & 1641 & Awu/Deception Isl. & Long Island & 258 & 1649 & $1638-63$ & 6 \\
\hline 14 & 1622 & unknown & & & & & \\
\hline 15 & 1600 & Huyanaputina & & & & & \\
\hline 16 & 1595 & Ruiz/Raung? & & & & & \\
\hline 17 & 1542 & unknown & Billy Mitchell & 336 & $1520,1588,1624$ & $1478-1639$ & 6 \\
\hline 18 & 1452 & Kuwae & & & & & \\
\hline 19 & 1343 & unknown & El Chichón & 538 & $1331,1341,1397$ & $1281-1444$ & $\geq 4$ \\
\hline 20 & 1334 & unknown & El Chichón & 538 & $1331,1341,1397$ & & $\geq 4$ \\
\hline 21 & 1286 & unknown & Tarawera & 724 & 1283 & & 5 \\
\hline 22 & 1279 & unknown & Tarawera & 724 & 1283 & $1267-97$ & 5 \\
\hline 23 & 1269 & unknown & Lolobau & 802 & 1254 & $1188-1281$ & 4 \\
\hline 24 & 1259 & El Chichón & Lolobau & 802 & 1254 & & 4 \\
\hline 25 & 1231 & unknown & & & & & \\
\hline 26 & 1190 & unknown & Billy Mitchell & 870 & $1165,1166,1188$ & $1044-1236$ & $5+$ \\
\hline 27 & 1171 & unknown & Billy Mitchell & 870 & $1165,1166,1188$ & $1044-1236$ & $5+$ \\
\hline 28 & 1108 & unknown & Guagua Pichincha & & $\begin{array}{c}1044,1090,1120,1139 \\
1155\end{array}$ & $1037-1159$ & $\geq 4$ \\
\hline 29 & 965 & unknown & Pelee/Dakataua? & 1108 & $\begin{array}{c}902,917,963 / 900,919 \\
958\end{array}$ & 890-990/779-1019 & $\geq 4$ \\
\hline 30 & 687 & unknown & Rabaul & 1346 & 664 & 536-893 & 6 \\
\hline 31 & 578 & unknown & & & & & \\
\hline 32 & 543 & unknown & & & & & \\
\hline 33 & 445 & unknown & Ilopango & 1642 & 416 & $134-638$ & 6 \\
\hline 34 & not dated & & & & & & \\
\hline 35 & 311 & unknown & & & & & \\
\hline 36 & 244 & unknown & Ambrym & 1822 & 221 & $39 \mathrm{вC}-425$ & $6+$ \\
\hline 37 & 177 & unknown & Taupo & 180 & & & \\
\hline 38 & & not dated & & & & & \\
\hline 39 & 132 & unknown & & & & & \\
\hline 40 & & not dated & & & & & \\
\hline
\end{tabular}

*Radiocarbon-dated events from Simkin and Siebert (1994), calibrateded on the basis of Stuiver and others (1998a).

Karlöf and others (2000) dated this peak to an unknown eruption in AD 639. Oerter and others (2000) assigned the same event to AD 687. The peak shows up in the nss-sulphate records of B32 and B31 and was dated by Traufetter and others (in press) at AD $685 \pm 15$. Peak 31 was dated by Karlöf and others (2000) at AD 540, where the eruption could be the Rabaul eruption, radiocarbon-dated at 1346 BP in Simkin and Siebert (1994). Oerter and others (2000) assigned this peak to AD 581. Traufetter and others (in press) assigned the corresponding nss-sulphate peak in B32 and B31 to $\mathrm{AD} 587 \pm 16$. Peak 32 is not present in the $\mathrm{CV}$ firn core because the core did not reach this horizon. Peak 32 is assigned to AD 544 by Oerter and others (2000) and dated by Traufetter and others (in press) at AD $542 \pm 17$. Peak 31, dated at AD 540, in core CV (Karlöf and others, 2000) is not related to the same event as peak 32, dated at AD 544, in core B33 by Oerter and others (2000). As we follow the chronology of Traufetter and others (in press) in this paper, we assigned peaks 30 and 31 to AD 687 and 581 instead of AD 642 and 540 as in Karlöf and others (2000). The Rabaul eruption was radiocarbon-dated at $1410 \mathrm{BP}$ in Simkin and Siebert (1994). Calibration brings the eruption peak in the $2 \sigma$ interval AD 536 (664) 893 where AD 664 is the calibrated date. Contrary to Karlöf and others' (2000) suggestion of Rabaul as a candidate for peak 31 (in this paper dated as AD 581), we think it less likely (but still within the $2 \sigma$ confidence interval) that peaks 31 and 32 are related to an eruption of Rabaul. We propose Rabaul as a candidate for the AD 687 eruption event (peak 30). Peak 33 is dated to AD 445. In Simkin and Siebert's (1994) chronology, a strong eruption (VEI 6) of Ilopango is radiocarbon-dated at $1642 \mathrm{BP} \pm 100$ years. This date is now estimated to have been in the $2 \sigma$ interval AD 134 (416) 638 (Dull and others, 2001), where the year AD 416 has highest probability, making it a good possibility for peak 33 .

The remaining events, peaks 41-49, are compared with 
the Dome $\mathrm{C}$ scale. This time-scale has an accuracy of 10 200 years in the period AD 1177 to 10 kyr BP (Schwander and others, 2001). For one event, peak 46, which has the largest amplitude, we present an estimate of the age based on average annual accumulation. Peak 46 occurs at $147 \mathrm{~m}$ (105.38 m w.e.) depth in core M150. Based on the average annual precipitation from present to AD 445, peak 46 would have an age of 420 BC. Simkin and Siebert's (1994) chronol- ogy does not contain a suitable event around this date. The event has been detected as one of the tie points in the DEP data of Dome $\mathrm{C}$ and the Vostok ice core. As a tie point, the age of this event is estimated to be $390 \mathrm{BC}$. According to the flow model of Dome $\mathrm{C}$, the event related to peak 46 took place in 364 BC. For consistency, we adopted the flow-model age as we used the Dome $\mathrm{C}$ flow-model time-scale for more eruptions.

MS received 13 November 2003 and accepted in revised form 9 March 2004 